\title{
A LIFECYCLE COST-DRIVEN SYSTEM DYNAMICS APPROACH FOR CONSIDERING ADDITIVE RE- MANUFACTURING OR REPAIR IN AERO-ENGINE COMPONENT DESIGN
}

\author{
Lawand, Lydia (1); Al Handawi, Khalil (1); Panarotto, Massimo (2); Andersson, Petter (3); \\ Isaksson, Ola (2); Kokkolaras, Michael $(1,2)$ \\ 1: McGill University; 2: Chalmers University of Technology; 3: GKN Aerospace Systems Sweden
}

\begin{abstract}
Aero-engine component design decisions should consider re-manufacturing and/or repair strategies and their impact on lifecycle cost. Existing design approaches do not account for alternative production technologies such as the use of additive manufacturing in life extension processes. This paper presents a modeling and optimization methodology for examining the impact of design decisions in the early development stage on component lifecycle cost during the in-service phase while considering the potential use of additive manufacturing in life extension strategies. Specifically, a system dynamics model is developed to assess different end-of-life scenarios. Finally, an optimization problem is formulated and solved to minimize lifecycle cost with respect to design variables related to remanufacturing.
\end{abstract}

Keywords: Computational design methods, Additive Manufacturing, Product-Service Systems (PSS)

\section{Contact:}

Kokkolaras, Michael

McGill University

Mechanical Engineering

Canada

michael.kokkolaras@mcgill.ca

Cite this article: Lawand, L., Al Handawi, K., Panarotto, M., Andersson, P., Isaksson, O., Kokkolaras, M. (2019) 'A

Lifecycle Cost-Driven System Dynamics Approach for Considering Additive Re-Manufacturing or Repair in Aero-Engine Component Design', in Proceedings of the 22nd International Conference on Engineering Design (ICED19), Delft, The Netherlands, 5-8 August 2019. DOI:10.1017/dsi.2019.140 


\section{INTRODUCTION}

Design plays a substantial role in determining a component's lifespan based on possible end-of-life (EoL) scenarios. This impacts in turn the lifecycle cost of a component, and thus its alignment with circular economy (CE) principles and objectives. $\mathrm{CE}$ is an economic model that encourages closed loop resource flow of various processes throughout a component's lifecycle (MacArthur Foundation, 2017; Garmulewicz et al., 2018). Moreover, the CE paradigm highlights the role of design in retrieving lost value of components throughout the in-service phase and impacting resource consumption within the industrial system, hence its ability to increase profit (Lindahl et al., 2006). For example, designing a component with EoL scenario such as reuse or re-manufacture is preferred to replacement as it offers both environmental and cost benefits due to the reduction in raw material consumption.

One possible way of achieving CE objectives is through designing components with extended lifespan, reducing thus the number of parts required throughout the system's in-service phase. Since component design impacts cost at various stages of its lifecycle, design decisions should aim at minimizing component lifecycle cost (LCC). However, rapid changes in technology and customer preferences complicate the design decision even more. In a market with rapid changes, initial product design might become obsolete by the manufacturing stage. Therefore, in order to reduce economic losses, design decisions must result in products with high degree of changeability (Fricke and Schulz, 2005).

Additive manufacturing (AM) provides an opportunity for considering novel repair and remanufacturing strategies that may extend the useful life of components and products. Life extension (LE) processes aim at maintaining the value of products during its lifecycle (Leino, Pekkarinen \& Soukka). Different LE strategies in which AM technologies have been implemented are listed below in order of increasing recovery efficiency.

- Recycling: allows reuse of materials from used components resulting in the loss of the identity and functionality of parent components (Thierry and Salomon, 1995).

- Repair: returns used components to working order. Quality may be generally lower than that of most products with the exception of critical aerospace related components, where certification regulations require same-level quality. Repair involves fixing and/or replacement of parts (Thierry and Salomon, 1995).

- Refurbishing: restoring the component up to a specified quality. Quality standards are less rigorous than those for new products (Thierry and Salomon, 1995). Reconditioning may return a product to like-new quality, but the process may not disassemble and clean all components; this distinguishes it from re-manufacturing.

- Re-manufacturing/overhaul: restoring the component to a quality as rigorous as those for new products. It involves intensive inspection and testing (Thierry and Salomon, 1995; Gray and Charter, 2007).

- Upgrading: improving component's functionality through taking advantage of technological developments (Gray and Charter, 2007).

At the same time, the interest of original equipment manufacturers (OEM) in increasing the modes of availability of their products has introduced the product-service systems (PSS) paradigm. This paradigm favors LE strategies during the early stages of product development. As firms base their decisions on profits, both costs and revenues are used as key indicators of the component's viability and provide valuable information to product designers. In this study, only costs associated with components throughout their in-service phase are considered.

Typically, most components are designed as either repair/replace components or through-life components. The motivation behind the research presented here is to provide support for design flexibility so that possible migration to different EoL scenarios, such as extending the component's lifespan, can be considered. One way this could be achieved is through identifying the utilization of AM in component LE processes.

The research presented in this paper aims at addressing two main questions:

1. What are the main cost drivers that impact the use of AM processes in CE principles such as repair, re-manufacture, refurbishment, recycle, and upgrade?

2. What are the design attributes associated with AM recovery strategies, and how can these be integrated in the design process? 
To investigate these questions, this paper presents the development and use of a model for examining the impact of design decisions in the early development stage on components' LCC during the in-service phase while considering the potential use of AM technology in LE of components.

\section{BACKGROUND}

Several applications in the AM literature consider LE of components, which can be helpful in identifying the key characteristics of components recovered by AM processes (Lahrour \& Brissaud, 2018). Both AM-related features and component characteristics should be considered for efficient and effective application of AM LE processes. Based on literature, cost drivers of different AM LE processes are categorized into costs due to resource availability, quality assurance, process characteristics, component accessibility, and downtime involved (Matsumoto et al., 2016; Giurco et al., 2014). Moreover, decisions on other design features such as the deposited part geometry and characteristics, its functional and spatial compatibility as well as AM process parameters need to be considered (Le, Paris \& Mandil, 2018; Adams, , 2016; Chakraborty, Mondal \& Mukherjee, 2017).

Introduction of AM has offered opportunities throughout the value chain such as the reduction of energy and resource consumption compared to conventional manufacturing methods. Tang et al. (2016) presented a framework for environmental impact analysis of AM processes and compared it with CNC machining. They showed that AM processes consume less energy and generate fewer $\mathrm{CO} 2$ emissions to produce a part than $\mathrm{CNC}$ milling. Moreover, $\mathrm{AM}$ has $\mathrm{CE}$ potential through product customization (reducing production of unnecessary parts), product recovery and the design of components with extended lifespan. In addition to this, it reduces the time to market, shortens assembly chains, and has the ability to produce complex parts (Kellens et al., 2017; Le, Paris \& Mandil, 2018). However, despite this potential, there are also significant barriers to the use of AM in a CE context. These include the speed, cost and quality of products manufactured as they are greatly impacted by market and requirement changes (Garmulewicz et al., 2018; Tateno \& Kondoh, 2017; Hollander, Bakker \& Hultink, 2017; Kwak \& Kim, 2012).

At the strategic level, decision-makers should understand the evolution of the recovery system over time and its impact on component LCC. In aerospace applications, decisions on components' LCC and their availability are highly critical and challenging as limited cost data is available at early stages of the design process (?). Other studies consider an active re-manufacturing product design process that takes recycle, reuse, disassemble and environmental load into consideration during the design stage resulting in products with environmental friendly characteristics (Wang, Zhang). Results have showed that currently existing approaches suffer from a high degree of uncertainty and fail to account for technological advancement such as the use of AM in LE processes. Furthermore, a number of tools and techniques have been published by academics on issues such as changes in market demand, EoL condition of components and product designs. However, there is no literature on how these tools relate to the decision process. Most studies assess re-manufacturing from an economic perspective. Environmental factors have received significant attention in the assessment of re-manufacruring strategies as well, while social factors were often neglected (Goodall, Rosamond \& Harding, 2014).

\section{MODEL METHODOLOGY}

The objective of the work presented in this paper is to develop a model that accounts for component LCC when considering alternative re-manufacturing and/or repair solutions early in the design process. Manufacturing parameters are tightly connected to quality and inspection intervals. Therefore, the first step of our methodology is the identification of design variables and parameters that are critical to the AM process. A system dynamics (SD) model is then developed to study the interrelations between the extracted component's lifespan and different costs throughout the in-service phase. This model is used for evaluation of different EoL scenarios using LCC as the key indicator of the system's efficiency. Finally, an optimization problem is solved to minimize LCC with respect to design variables. Figure 1 illustrates the proposed methodology.

The proposed model is demonstrated by means of a case study involving a turbine rear structure (TRS), one of the most critical structural load bearing components of an aero-engine. Changes in load requirements or airplane structure throughout the in-service phase impact the performance of the TRS, hence 
its lifespan. The life extension of the TRS is achieved through additive deposition of a circumferential stiffener on the outer casing. This stiffener strengthens the structure and thus extends the service intervals. The key dimensions (and design variables) of this geometrical configuration are outlined in Figure 2.

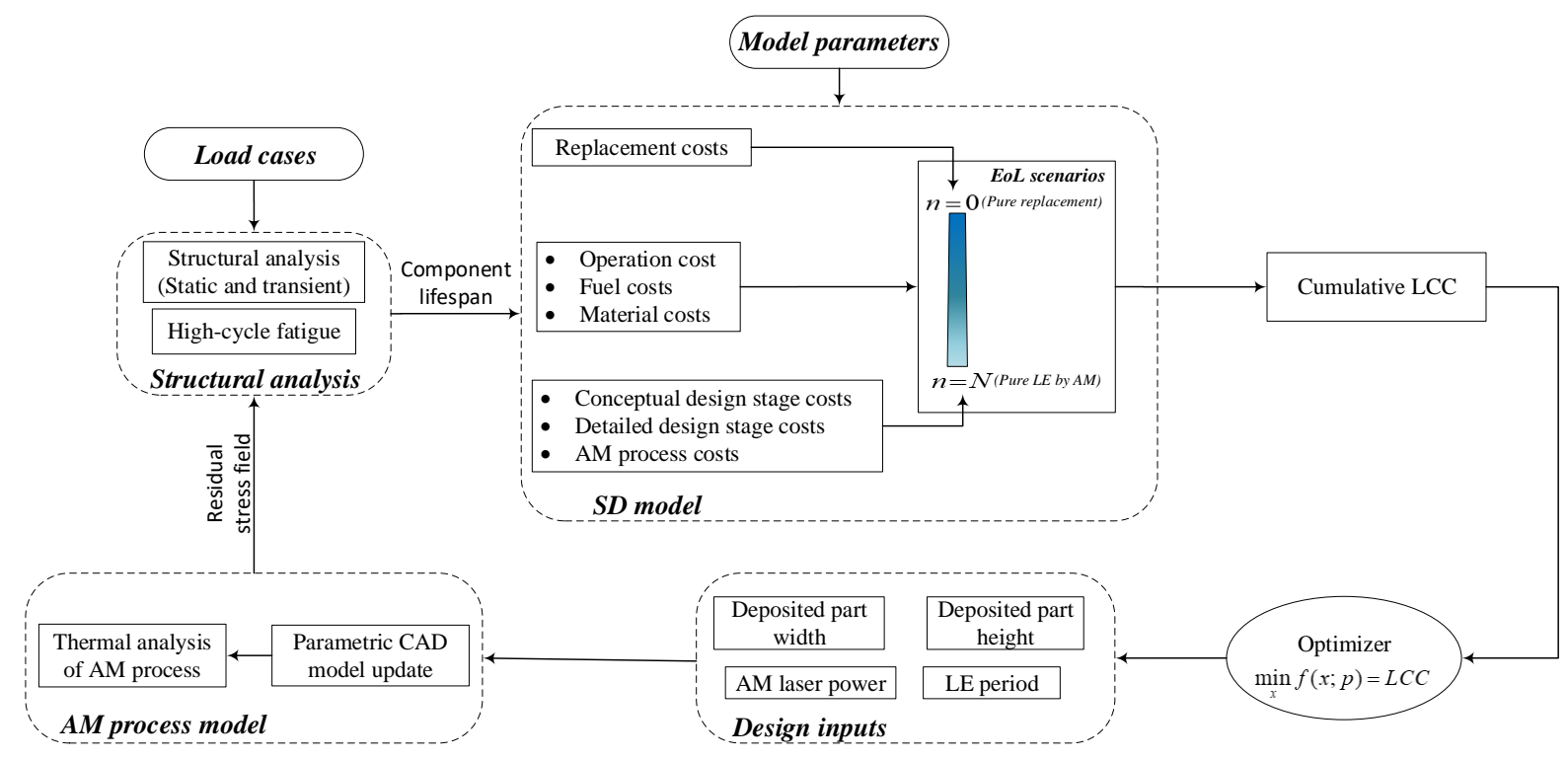

Figure 1. LCC optimization methodology

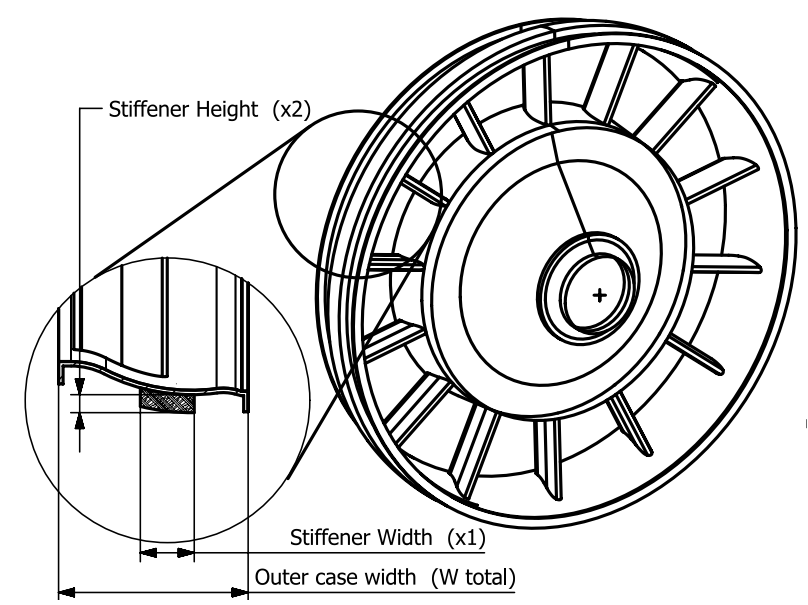

Figure 2. Schematic of the TRS and deposited stiffener

A model for studying the dynamics of different EoL scenarios was developed in which LCC is used to asses each scenario. The model includes cost drivers such as material and fuel costs, LE and replacement lifespans, operators hourly rates and AM process time involved throughout the in-service phase. Moreover, several design attributes are considered in the model such as the deposited part geometry and material type, AM process parameters used and the time period in which LE processes are performed.

\subsection{System dynamics model for a turbine rear structure}

System dynamics can be used in long-term, strategic models where capturing information flow and feedback are important considerations. SD models are well suited to incorporate qualitative aspects of behavior that, while difficult to quantify, might significantly affect the performance of a system (Panarotto, Wall \& Larsson, 2017). Several examples are found in literature on the use of SD models for management of engineering and medical projects (Chritamara, Ogunlana \& Bach, 2002; Zhang et al., 2017). These mainly include assessment of the impact of different design features on project 
performance, determining costs of components as well as assisting in pricing decisions and policies formulation.

The SD model is structured by causal loops that define correlations within the system under study. As shown in Figure 3, throughout the system's in-service phase, changes in requirements will impact the component's designed lifespan, and thus its LCC. One possibility to reduce LCC is to extend the component's lifespan using AM. Applying AM LE strategies increases the lifespan of the component with the aim to decrease LCC as fewer number of replacement processes will be required during the in-service phase. This control loop is called a balancing loop. However, in the long run, using AM in LE processes introduces structural defects into the component due to thermal conditions associated with the manufacturing process. This will increase risk of component failure, which in turn may increase the need for component replacement, thus negatively impacting its LCC. Moreover, as AM processes involve deposition of material onto the parent component, the overall component weight will increase, resulting in an increase in the system's fuel consumption. This, along with costs of the material used in the LE process, will impact both component- and system-level LCC.

One of the most important questions is which of these loops is dominant. In order to make effective decisions, it is crucial to understand the unintended consequences of alternative design and manufacturing solutions, hence prevent them from becoming the dominant loop in the system. The aforementioned SD approach was applied on a case study examining the impact of changing load case requirements on a TRS lifespan while considering AM LE processes.

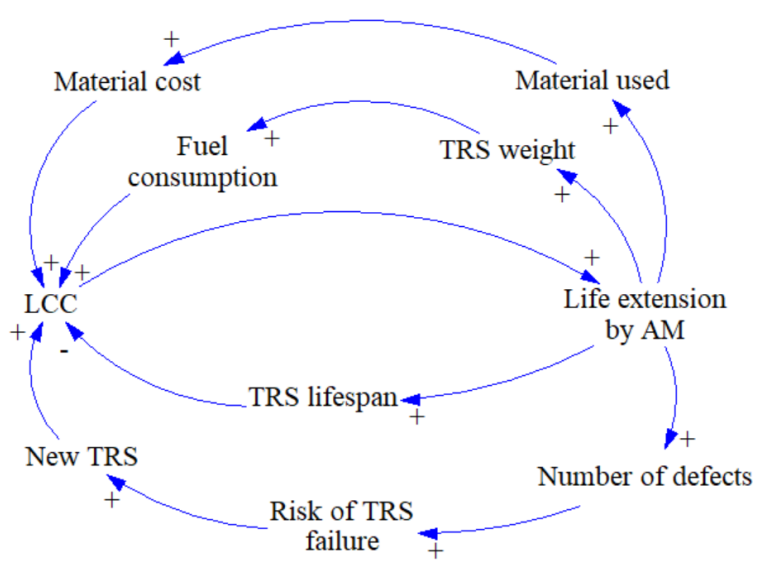

Figure 3. Causal loops describing relation between TRS LCC and its LE by AM. (+) denotes that the two variables move in the same direction (an increase in one variable results in an increase in the other) and (-) denotes that variables move in the opposite direction

Variables such as fuel and material prices used in the proposed model are dynamic. Various price forecasting models and techniques can be found in the literature. These techniques include time series and data mining from which Artificial Neural Network (ANN) is the most popular as they are able to resolve indeterminate relations between input and output variables, approximate complex nonlinear functions and can implement multiple training algorithms. However, several disadvantages are associated with ANNs as they require a certain minimum amount of data and may result in over-fitting when large data-sets are available. Hybrid models are currently being developed that overcome the short comings of these models and provide reliable and accurate forecasting. Decisions on the forecasting technique adopted depends on the level of accuracy required and computational cost that can be afforded. In order to consider the dynamic evolution of such prices in the proposed model, data-fitting models over a 20year period (1998-2018) were integrated into the model (U.S. Department of Energy Office of Energy Efficiency \& Renewable Energy, 2017; Thomson Reuters Datastream, 2018).

A schematic of the SD model illustrating the three EoL scenarios and basic elements contributing to the LCC of each scenario is shown in Figure 4. The main cost drivers and design attributes associated with AM LE strategies and component replacement procedures identified from literature are integrated in the developed model. As shown in Figure 4, the model starts with design decisions regarding AM process parameters, deposited part geometry, material type used and the time period in which AM LE 
processes are performed. These decisions will in turn impact different cost drivers resulting in a change in the cumulative cost at the end of the system's in-service period.

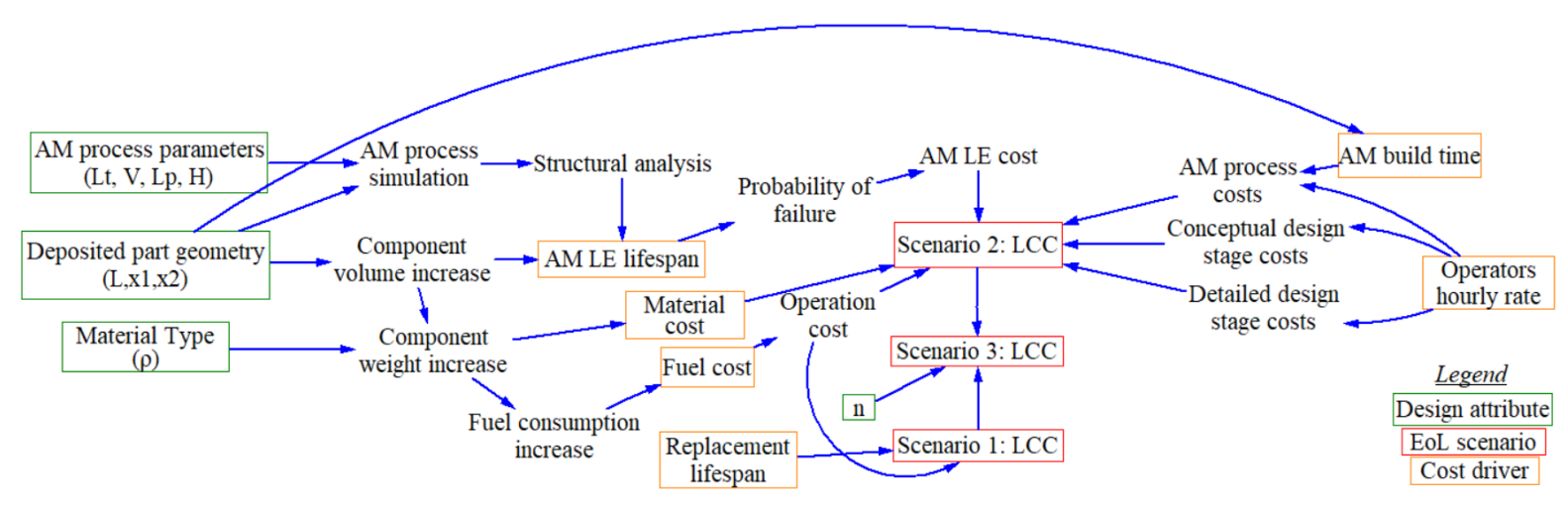

Figure 4. Schematic of the developed SD model

The main assumptions made in the developed model are as follows:

- Component's lifespan calculation is based on structural considerations, mainly residual stresses resulting from the AM process. These are functions of the deposited part geometry and AM process parameters (Al Handawi et al., 2018).

- $\quad$ AM LE costs are linearly interpolated and proportional to the component's probability of failure calculated using weibull distribution with shape parameter of 2 and scale parameter $(\lambda)=$ (inservice phase) $\times(-\ln (0.9))^{-0.5}$ (Thomsen et al., 2017).

- Part deposited on the outer casing of the TRS is assumed to be a circumferential rectangular stiffener.

- For the sake of simplicity, material type is treated as a parameter considering only specifications of Inconel 718 in the model, hence avoiding the use of categorical variables in the optimization problem. However, parametric studies with respect to material choice can be conducted in a straightforward manner.

- Only costs of the conceptual design, detailed design, manufacturing, operation and maintenance stages as well as different component EoL scenarios were considered in the LCC calculation (Fera et al., 2017). Costs of marketing and shipping stages were not considered as they are not applicable to this case study. Moreover, costs of installation and after-sale stages were not included as further research is required on suitable methods for estimating costs of these stages.

- It is assumed that the aircraft, on which the engine is mounted, flies equal number of cycles every year.

- It is assumed that for each $1 \%$ weight increase, 0.75 litres of fuel are consumed extra (Capehart, 2007).

- Deposited layer thickness is assumed to be independent of AM process parameters.

- The start time of LE processes is treated as a parameter.

LCC calculation depends on values that will most likely change with time such as maintenance costs and operation costs. Therefore, present value (PV) approach was used to assess LCC through comparison of the value of currency at different times. It allows the use of a reference year value cost approach. The PV approach discounts all future costs with a given discount rate and then sums them according to

$$
P V=\sum_{t=0}^{N} \frac{C_{t}}{(1+r)^{t}},
$$

where $C_{t}$ is the sum of all costs in year $t, r$ is the discount rate and $N$ is the in-service period. As LCC are discounted to their PV, selection of a suitable discount rate is a crucial aspect in LCC analysis. Available literature in this area offers little recommendations regarding the final selection of an appropriate rate. The time value of money, expressed as a discount rate, depends on inflation, cost of capital, investment opportunities and personal consumption preferences (Spickova and Myskova, 2015). In this study, the discount rate used in PV calculations is set to $4 \%$. 


\subsection{Sample model results}

Three EoL scenarios are simulated for the TRS case study:

1. Replace the TRS component at the end of its designed lifespan.

2. Extend the life of the TRS component through deposition of Inconel 718 (nickel alloy), same material as the parent component, using AM.

3. Combination of both component replacement and LE processes using AM.

A design variable was introduced in Scenario 3 to represent the time period, within the in-service phase, in which LE processes are performed. The LCC of the TRS calculated at each year throughout the system's in-service phase are cumulatively determining to their PV. Each of the EoL scenarios was simulated for different inputs using the developed SD model displayed in Figure 3. The SD model was translated to the corresponding element blocks shown in Figure 4. Assumptions documented in Section 3.1 were then used as the basis for quantitative analysis of the TRS case study. Results obtained for EoL scenario 1 ensure that as the component's designed lifespan increases, fewer number of replacements are required, hence less spare parts needed decreasing LCC throughout the in-service phase (Figure 5(a)). For EoL scenario 2, increasing the thickness of the deposited part results in an increase in the component lifespan and a decrease in the number of LE processes required (Figure 5(c)). Moreover, the LE process cost is proportional to the geometry of the part deposited and depends on the fuel and material prices in the year at which the process is performed. However, it was concluded that the number of LE processes performed have a greater impact on the LCC than the increase in material and fuel costs due to the deposited part geometry. Finally, as shown in Figure 5(b), keeping deposited part geometry and component lifespan constant, the more the time period in which LE processes are performed during the system's in-service phase, the higher is the LCC. However, we should keep in mind that LE process costs highly depend on deposited part geometry and AM process parameters.

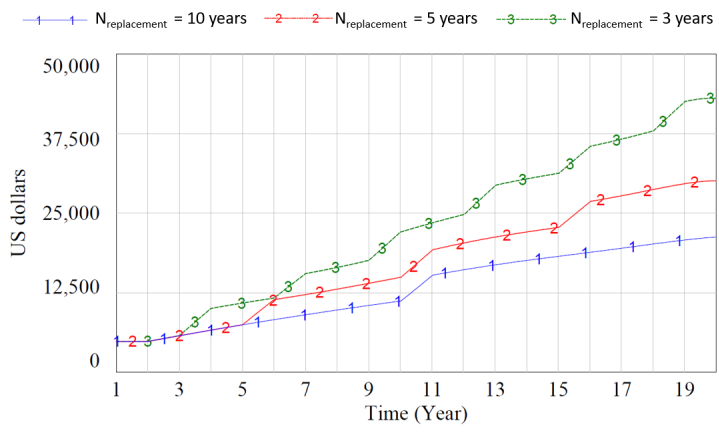

(a) EoL Scenario 1

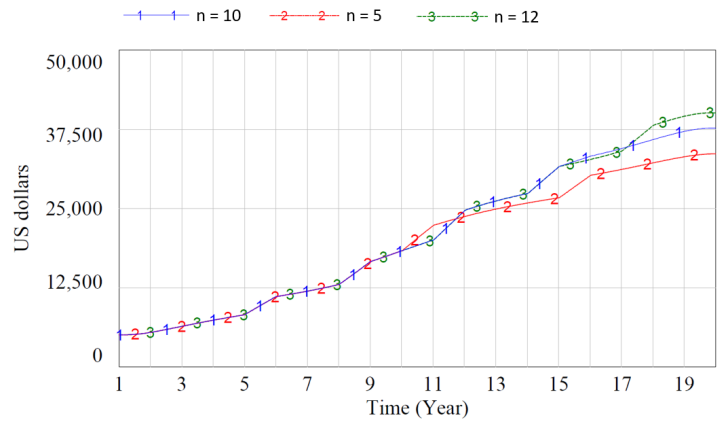

(b) EoL Scenario 3 with $N_{\text {replacement }}=5$ years, $N_{L E}=$ 3 years and Design $=20 \mathrm{~cm} \times 0.4 \mathrm{~cm} \times 1 \mathrm{~cm}$

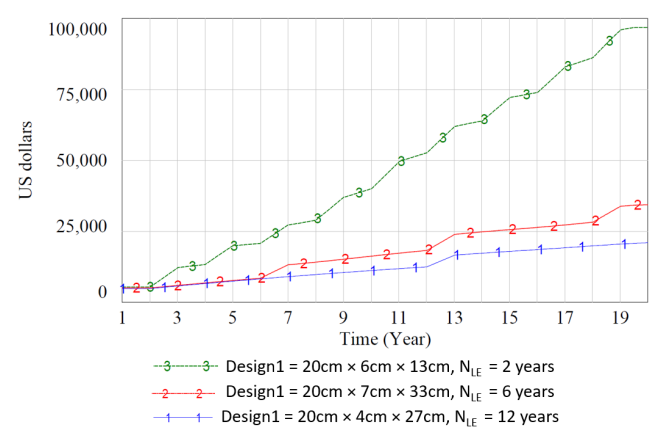

(c) EoL Scenario 2

Figure 5. Present value of lifecycle cost over a 20-year period for different EoL scenarios

\section{LIFECYCLE COST OPTIMIZATION}

The 4 design variables consist of geometric variables governing the width $\left(x_{1}\right)$ and height $\left(x_{2}\right)$ of the deposited stiffener, AM process parameter defining the laser power used $\left(L_{p}\right)$, and the time period in which LE processes are performed $(n)$. The constraints ensure that the increase in weight due to the 
additively deposited part does not exceed $10 \%$ of the parent component weight. Bounds on the LE lifespan and the time period in which LE processes are performed were specified. Further constraints were placed on the deposited part width and thickness to ensure that it is contained within the bounds of the existing TRS outer case while satisfying the AM process specifications. Moreover, range of the laser power used in the AM process was chosen to ensure comparable melt pool dimensions to those of the deposited part. Taking these constraints into consideration, the objective of the developed optimization problem is to minimize LCC of the TRS component throughout its in-service phase:

$$
\begin{aligned}
& \underset{\mathbf{x}}{\operatorname{minimize}} L C C=f(\mathbf{x}) \\
& \text { where } \mathbf{x}=\left[x_{1}, x_{2}, L_{p}, n\right] \\
& \text { subject to } \\
& g_{1}(\mathbf{x})=x_{1} x_{2}-0.1 W_{i} /(\rho \times L) \leq 0 \text { (geometric constraint) } \\
& g_{2}(\mathbf{x})=N_{L E}\left(x_{1}, x_{2}, L_{p}\right)-N \leq 0 \text { (model constraint) } \\
& 0 \leq n \leq N=20 \text { years } \\
& 10 \mathrm{~cm} \leq x_{1} \leq X_{\text {total }}=40 \mathrm{~cm} \\
& 2 \mathrm{~cm} \leq x_{2} \leq 10 \mathrm{~cm} \\
& 3,500 \mathrm{~W} \leq L_{p} \leq 4,000 \mathrm{~W}
\end{aligned}
$$

In the formulated optimization problem $W_{i}$ is the initial weight of the TRS, $\rho_{m}$ is deposited material density, $L$ is deposited part length, $N_{L E}$ is AM LE lifespan, $N$ is in-service phase and $X_{\text {total }}$ is the outer TRS case width. A surrogate is initially constructed for the data obtained from the structural analysis model which was then integrated into the SD model to reduce computational costs during optimization. The optimization problem is solved using the Mesh Adaptive Direct Search (MADS) algorithm (Audet and Dennis, 2006). Five different initial guesses were chosen randomly, and two local optima were obtained; the best of the two is listed in Table 1. Both constraints are active. This is because the lower the deposited part height, the less the required number of additively deposited layers, therefore less exposure of the component to thermal cycles due to the AM process that impact the component's structural integrity. Moreover, depending on the geometry of the additively deposited part, performing several LE processes results in lower costs than replacing a single component. Therefore, there is an interesting trade-off between number of LE processes performed using AM and the cumulative LCC of the component throughout the in-service phase.

Table 1. Best local optimizer obtained using MADS

\begin{tabular}{ccccc|c}
\hline & $x_{1}(\mathrm{~cm})$ & $x_{2}(\mathrm{~cm})$ & $L_{p}(\mathrm{~W})$ & $\mathrm{n}($ years $)$ & LCC $($ USD) \\
\hline Optimizer/ optimum & 40 & 6.8 & 3,500 & 16 & 26,795 \\
\hline
\end{tabular}

The case study used in this paper to demonstrate capabilities of the developed methodology is representative of the aerospace industry and based on a real case provided by GKN Aerospace. Moreover, the proposed LCC model provides an overall view of the costs throughout the lifecycle of a component based on geometry. As a result of this, the developed model can be extended beyond an individual case and be used in LCC estimation of components with different geometries. This would help generalize the concept and make it applicable to any industrial case, regardless of the product's structure and specific parameter values. However, cost models need to be generalized to include different material types, AM process types as well as fuel and material prices. Finally, to validate a broader application of the proposed methodology, it must be tested on other case studies.

\section{CONCLUSIONS AND FUTURE WORK}

Life extension of components is typically considered during their lifecycle without previous planning. In this work, we demonstrated a modeling and optimization methodology for providing decision-making flexibility through considering different end of life (EoL) scenarios. Specifically, we developed a SD model that simulates different EoL scenarios and used it to link re-manufacturing and repair strategies to design specifications and lifecycle cost optimization. 
Future work includes acquiring cost data to increase the accuracy of the developed LCC model. Moreover, higher fidelity models of the AM process simulation and structural analysis will be utilized in the developed SD model. Furthermore, design alternatives can be identified and evaluated through tradespace exploration based on calculations of LCC and degree of changeability. This will allow expansion of the knowledge base through incorporating product usage data and failure information. Finally, future work could treat the deposited part geometry and orientation as design variables that are determined using topology optimization.

\section{REFERENCES}

Adams, H. (2016), "Ion fusion formation : an alternative fastening conference \& exhibition", SAE International

Al Handawi, K., Lawand, L., Andersson, P., Brommesson, R., Isaksson, O. and Kokkolaras, M. (2018), "Integrating additive manufacturing and repair strategies of aeroengine components in the computational multidisciplinary engineering design process", NordDesign Conference, Linköping, Sweden

Angioletti, C., Sisca, F., Luglietti, R., Taisch, M. and Rocca. R. (2016), "Additive manufacturing as an opportunity for supporting sustainability through implementation of circular economies", Industrial Systems Engineering, pp. 25-30.

Audet, C. and Dennis Jr., J.E. (2006), "Mesh adaptive direct search algorithms for constrained optimization", SIAM Journal on Optimization, Vol. 17 No. 1, pp. 188-217.

Capehart, B. (2007), "Encyclopedia of Energy Engineering and Technology", CRC Press, ISBN 978-0-8493-3653-9

Chakraborty, K., Mondal, S. and Mukherjee, K. (2017), "Analysis of product design characteristics for remanufacturing using Fuzzy AHP and Axiomatic Design”, Journal of Engineering Design, Vol. 4828. https://doi.org/10.1080/09544828.2017.1316014

Chritamara, S., Ogunlana, S. and Bach, N. (2002), "System dynamics modeling of design and build construction projects", Construction Innovation, Vol. 2, pp. 266-295. https://doi.org/10.1108/14714170210814801

Ellen MacArthur Foundation (2017), www.ellenmacarthurfoundation.org, last accessed December 15, 2018

Fera, M., Friggiero, F., Costabile, G., Lambiase, A. and Pham, D. (2017), "A new mixed production cost allocation model for additive manufacturing (MiProCAMAM)", International journal of advanced manufacturing technology, https://doi.org/10.1007/s00170-017-0492-x

Fricke, E. and Schulz, A. (2005), "Design for Changeability (DFC):Principles To Enable Changes in Systems Throughuot their Entire Lifecycle", Systems Engineering, Vol. 8. https://doi.org/10.1002/sys.20039

Garmulewicz, A., Holweg, M., Veldhius, H. and Yang, A. (2018), "Disruptive technology as an enabler of the circular economy: what potential does 3D printing hold?", California Management Review, Vol. 60, pp. 112-132, https://doi.org/10.1177/0008125617752

Giurco, D., Littleboy, A., Boyle, T., Fyfe, J. and White, S. (2014), "Circular economy: questions for responsible minerals, additive manufacturing and recycling of metals", Resources, Vol. 3, pp. 432-453. https://doi.org/10.3390/resources3020432

Goodall, P., Rosamond, E. and Harding, J. (2014), "A review of the state of the art in tools and techniques used to evaluate remanufacturing feasibility", Journal of Cleaner Production, Vol. 81, pp. 1-15. https://doi.org/10.1016/j.jclepro.2014.06.014

Gray, C. and Charter, M. (2007), Remanufacturing and Product Design, The centre for sustainable design, UK.

Hollander, M., Bakker, C. and Hultink, E. (2017), "Product design in a circular economy: development of a typology of key concepts and terms", Journal of Industrial Ecology, Vol. 21. https://doi.org/10.1111/jiec.12610

Kellens, K., Baumers, M., Gutowski, T., Flanagam, W., Lifset, R. and Duflou, J. (2017), "Environmental dimensions of additive manufacturing: mapping application domains and their environmental implications", Journal of Industrial Ecology, Vol. 21, pp. 49-68. https://doi.org/10.1111/jiec.12629

Kwak, M. and Kim, H. (2012), "Market positioning of remanufactured products with optimal planning for part upgrades", Journal of Mechanical Design, Vol. 135. https://doi.org/10.1115/1.4023000

Lahrour, Y. and Brissaud, D. (2018), "A technical assessment of product/component re-manufacturability for additive remanufacturing", 25th CIRP Life Cycle Engineering Conference, Vol. 69, pp. 142-147. https://doi.org/10.1016/j.procir.2017.11.105

Le, V., Paris, H. and Mandil, G. (2018), "Extracting features for manufacture of parts from existing components based on combining additive and subtractive technologies", International Journal on Interactive Design and Manufacturing (IJIDeM), Vol. 12, pp. 525-536. https://doi.org/10.1007/s12008-017-0395-y

Leino, M., Pekkarinen, J. and Soukka, R. (2016), "The role of laser additive manufacturing methods of metals in repair, refurbishment and remanufacturing - enabling circular economy", 9th International Conference on Photonic Technologies, Vol. 83, pp. 752-760. https://doi.org/10.1016/j.phpro.2016.08.077 
Lindahl, M., Sundin, E., Ostlin, J. and Bjorkman, M. (2006), “Concepts and definitions for product recovery: analysis and clarification of the terminology used in academia and industry", Innovation in Life Cycle Engineering and Sustainable Development, pp. 123-138, ISBN: 978-1-4020-4601-8

Matsumoto, M., Yang, S., Martinsen, K. and Kainuma, Y. (2016), "Trends and research challenges in remanufacturing", International Journal of Precision Engineering and Manufacturing-Green Technology, Vol. 3, pp. 129-142. https://doi.org/10.1007/s40684-016-0016-4

Panarotto, M., Wall, J. and Larsson, T. (2017), "Simulation-driven design for assessing strategic decisions in the conceptual design of circular PSS business models", Procedia CIRP, Vol. 64, pp. 25-30, https://doi.org/10.1016/j.procir.2017.03.026

Spickova, M. and Myskova, R. (2015), "Costs efficiency evaluation using life cycle costing as strategic method", Procedia Economics and Finance, Vol. 34 No. 15, pp. 337-343.

Tang, Y., Mak, K. and Zhao, Y. (2016), “A framework to reduce product environmental impact through design optimization for additive manufacturing”, Journal of Cleaner Production, Vol. 137, pp. 1560-1572. https://doi.org/10.1016/j.jclepro.2016.06.037

Tateno, T. and Kondoh, S. (2017), "Environmental load reduction by customization for reuse with additive manufacturing", 24th CIRP Conference on Life Cycle Engineering, Vol. 61, pp. 241-244. https://doi.org/10.1016/j.procir.2016.11.219

Thierry, M., Salomon, M., Nunen, J. and Wassenhove, L. (1995), "Strategic issues in product recovery management", California Management Review, Vol. 37 No. 2.

Thomsen, B., Kokkolaras, M., Mansson, T. and Isaksson, O. (2017), "Quantitative assessment of the impact of alternative manufacturing methods on aeroengine component lifing decisions", Journal of Mechanical Design, Vol. 139, pp. 1-10. https://doi.org/10.1115/1.4034883

Thomson Reuters Datastream. (2018), Nickel Monthly Price - US Dollars per Metric Ton, https://www.indexmundi.com/commodities/?commodity=nickel\&months=60, last accessed August 15, 2018

U.S. Department of Energy Office of Energy Efficiency \& Renewable Energy, (2017), Average Historical Annual Gasoline Pump Price, 1929-2015, https://www.energy.gov/eere/vehicles/fact-915-march-7-2016-averagehistorical-annual-gasoline-pump-price-1929-2015, last accessed August 10, 2018

Wang, L., Zhang, Z. and Chen, C. (2012), "Evaluation model for product green design based on active remanufacturing", Applied Mechanics and Materials, Vol. 215, pp. 583-587. https://doi.org/10.4028/www.scientific.net/AMM.215-216.583

Zhang, D., Feng, Z., Wang, C., Liu, Z., Dong, D., Zhou, Y. and Wu, R. (2017), "Modeling of temperature field evolution during multilayered direct laser metal deposition", Journal of Thermal Spray Technology, Vol. 26, pp. 831-845. https://doi.org/10.1007/s11666-017-0554-5

\section{ACKNOWLEDGMENTS}

The first, third and last authors are grateful for the partial support of their work by grants NSERC CRDPJ 479630-15 X-243027 and CARIC CRDPJ479630-15 X-243067. The work of the fourth author has been partially supported by European Union's Horizon 2020 research and innovation programme under grant agreement No 690608. Such support does not constitute an endorsement of the opinions expressed in this paper. Support from the Area of Advance Production at Chalmers is also acknowledged. 